\title{
PENJELASAN AJARAN DALAM \\ PRAJNA PARAMITA HDRAYA SUTRA (SIN CING)
}

\author{
Nyoto \\ SEKOLAH TINGGI AGAMA BUDDHA NEGERI SRIWIJAYA \\ mailnyoto@gmail.com
}

\begin{abstract}
Abstrak
Semua bentuk aktivitas yang dilakukan manusia pasti memiliki tujuan tertentu yang tidak diketahui oleh manusia disekitarnya. Begitu juga dengan aktivitas spiritual yang dilaksanakan umat Buddha. Umat Buddha Mahayana sangat meyakini dan menggap bahwa Pranja Paramita Hdraya Sutra adalah salah satu sutra hebat.

Pranja Paramita Hdraya Sutra adalah kotbah Buddha tentang percakapan Bodhisatva Avalokitesvara dengan Araht Sariputra yang membahas tentang cara mencapai Nirvana adalah dengan merenungi panca skhanda yang diliputi oleh sunya (kosong). Apabila manusia mampu membebaskan diri dari kebodohan dan kemelekatan maka manusia akan mencapai kebahagian abadi atau Nirvana dan biasa disebut dengan kekosongan atau sunyata.

Pranja Paramita Hdraya Sutra juga menjelaskan tentang sebab penderitaan dan jalan untuk melenyapkan penderitaan. Apabila penderitaan telah dilenyapkan maka kebijakasanaan sejati akan tercapai. Perenungan dan pelaksanaan Pranja Paramita Hdraya Sutra akan mengondisikan seseorang mencapai Nirvana.
\end{abstract}

\section{A. Latar Belakang Masalah}

Pandangan salah, pengetahuan yang sempit dan tidak mau belajar tentang kebenaran adalah sebagian faktor penyebab penderitaan. Salah satu faktor penyebab pandangan salah adalah keyakinan membuta terhadap satu ajaran. Ada sebagian manusia mudah percaya dengan sesuatu yang dianggapnya istimewa, memiliki kelebihan, memiliki kekuatan tertentu, bisa diterima logika dan orang lain mengatakan bahwa sesuatu itu hebat. Bagaikan seseorang yang sakit kemudian mendapatkan air dari seorang dukun dan mempercayai bahwa air itu memiliki kekuatan untuk menyebuhkan penyakitnya tanpa mempertimbangkan dari mana asal air tersebut, bersih atau kotor, sehat atau tidak. Pola pikir yang mudah dipengaruhi dan tidak kokoh 
dalam pendirian akan memengaruhi tindakan atau perilaku dalam kehidupan sehari-hari.

Sebagian besar manusia selalu berharap hidup enak, tetapi malas dalam berusaha. Karena malas manusia mencari cara yang praktis agar keinginanya tercapai. Salah satu cara yang paling disukai adalah berharap mendapatkan berkah dari dewa, mantra, jimat dan lain sebagainya. Ketika seseorang mendapatkan saran dari orang lain dan dianggapnya akan mendatangkan berkah, maka manusia akan mudah percaya dan berusaha melaksanakan apa yang harus dilaksanakan dan apa yang menjadi pantangan.

Kemajuan zaman yang semakin canggih memengaruhi pola pikir manusian, karena manusia mudah mendapatkan informasi baik dari media cetak dan elektronik. Tetapi manusia lebih suka dengan informasi yang disukai misal info politik, hiburan dan ekonomi. Manusia menganggap bahwa informasi tentang bagaimana melatih diri dan mengendalikan diri tidak penting karena tidak mendatangkan materi. Banyak manusia yang melaksanakan aktifitas hanya berdarkan naluri untuk hidup dan memenuhi kebutuhan. Kebanyakan manusia akan berusaha mendekatkan diri pada Tuhan atau agamannya setelah mendapatkan musibah misalnya bangkrut, usaha yang tidak berkembang, masalah jodoh, kesehatan dan permasalahan hidup lainnya.

Dalam ajaran agama Buddha Mahayana dikenal satu sutra atau mantra yang dianggap memiliki kekuatan tertentu yang bisa menolong manusia dari bencana (penderitaan) yang dihadapi, sutra tersebut adalah Pranja Paramita Hdraya Sutra atau dalam bahasa Mandari dikenal dengan nama Po je po lo mi tou sin cing atau biasa dikenal dengan nama Sin Cing (Sutra Hati). Sutra ini banyak disalah artikan oleh umat Buddha sebagai jimat, misalnya dicetak kecil lalu dibuat liontin atau kalung yang dianggap bisa menjauhkan seseorang dari bencana.

Prajna Paramita Hdraya Sutra bukanlah mantra atau jimat yang dapat menjauhkan seseorang dari bencana. Sutra ini dibabarkan dengan tujuan menggali Bodhicitta manusia agar terbebas dari penderitaan atau merealisasi 
kebahagiaan abadi atau Nirvana. Bukan dengan menghafal atau membacanya saja, tetapi dengan mempraktikkan ajaran yang disampaikan oleh Bodhisatva Avalokitesvara kepada Araht Sariputra tentang sunya dan sunyata.

\section{B. PEMBAHASAN}

Prajna Paramita Hrdaya Sutra merupakan salah satu sutra yang sangat terkenal dalam agama Buddha Mahayana. Sutra ini bila diterjemahkan kedalam bahasa Indonesia dikenal dengan Sutra Hati atau Sin Cing dalam bahasa Mandarin. Sutra ini berisi tentang penjelasan Bodhisatva Avalokitesvara kepada Araht Sariputra tentang sunya dan sunyata. Konsep sunya dan sunyata berisi tentang penjelasan panca skhanda yang tidak kekal dan perenungan terhadap panca skhanda melalui meditasi adalah jalan menuju kekosongan (sunyata) atau Nirvana.

\section{Penjelasan samadhi untuk mencapai Nirvana}

Buddha Dharma mengajarkan bahwa hanya dengan melaksanakan meditasi seseorang akan mencapai Nirvana atau terbebasnya manusia dari penderitaan. Disebut Nirvana, karena terbebas dari nafsu yang disebut vana, keinginan. Secara harfiah, Nirvana berarti terbebas dari kemelekatan. Nirvana dapat juga diartikan sebagai padamnya keserakahan, kebencian dan kebodohan.

Dalam Prajna Paramita Hrdaya Sutra Bodhisatva Avalikitesvara menjelaskan bahwa melalui samadhi kebijaksanaan sejati seseorang akan dapat merealisasi Nirvana. Kondisi ini terjadi karena manusia yang melaksanakan samadhi dengan benar akan memahami fenomena yang ada akan muncul dan padam, selalu diliputi penderitaan. Dalam penjelasannya Bodhisatva Avalikitesvara mengatakan bahwa Beliau melihat panca skhanda adalah sunya (kosong). Dari penjelasan ini dapat diketahui bahwa manusia harus mengetahui bahwa panca skhanda atau batin dan jasmani adalah tidak kekal dan tidak ada inti yang kekal.

Dengan merenungkan panca skhanda melalui samadhi yang benar seseorang akan menyadari bahwa kemelekatan adalah penderitaan. Panca khandha (pali) atau panca skhanda (sanskerta) berasal dari kata panca 
dan khandha. Panca berarti lima dan khandha berarti kelompok/kumpulan. Jadi panca skhadha berarti lima kelompok pembentuk kehidupan, namun dilain kesempatan dalam pengajaranNya, Sang Buddha juga menyebutnya sebagai lima kelompok kemelekatan. Jadi, apa yang disebut sebagai makhluk hidup termasuk manusia, dalam pandangan Buddha Dharma adalah hanya merupakan perpaduan dari panca skhanda yang saling bekerja sama secara erat satu sama yang lain. Tidak ditemukan suatu atman/atta atau roh yang kekal dan abadi.

Satu materi lenyap dan ini menciptakan kondisi untuk timbulnya materi yang berikutnya dan begitu seterusnya dalam satu rangkaian sebab dan akibat. Tak terdapat satu bagian pun yang kekal di dalamnya. tidak ada sesuatu di belakangnya yang dapat disebut sebagai satu atta (pali) atau atman (skrt) yang kekal abadi, satu pribadi atau apa yang disebut sebagai aku. Dari penjelasan ini Bodhisatva Avalikitesvara menjelaskan bahwa dengan melaksanakan Samadhi dengan benar maka seseorang dapat terlepas dari kemelekatan dan mencapai Nirvana.

\section{Panca Skhanda adalah Sunya (kosong)}

Menurut pandangan Buddhis, apa yang manusia anggap sebagai makhluk, orang atau aku, hanyalah merupakan gabungan dari kekuatan atau energi phisik dan mental, yang selalu dalam keadaan bergerak dan berubah, yang terdiri dari lima unsur/kelompok kemelekatan (panca skhanda) penyusun kehidupan, yaitu :

a. Jasmani (rupa skhanda)

Bentuk benda yang terlihat dan dapat disentuh, suara, bebauan, rasa yang melalui lidah, termasuk juga gagasan dan konsepsi yang berada dalam pikiran. Jadi kelompok Jasmani mencakup semua bentukbentuk secara keseluruhan, yang berada di dalam tubuh. Semua unsur yang ada pada tubuh manusia akan muncul dan hilang karena tidak kekal.

b. Perasaan (vedana skhanda) 
Setiap perasaan yang bagaimanapun, baik di waktu yang lalu, yang akan datang, atau sekarang, di dalam atau di luar diri orang, kasar atau halus, rendah atau tinggi , jauh atau dekat, yang dipengaruhi oleh noda-noda dan pancingan kemelekatan; disebut kelompok perasaan yang dipengaruhi oleh kemelekatan.

c. Pencerapan (sanna skhanda)

Sanna berarti pencerapan. Keberadaannya dapat dianalisa ketika batin mencerap atau menerima ataupun mengenal rangsangan-rangsangan yang terjadi pada tubuh melalui suatu bagian dari otak. Pencerapan muncul dan hilang dan tidak kekal.

\section{d. Bentu-bentu pikiran (Sankhara skhanda)}

Pikiran sebenarnya juga sebuah indera sebagaimana halnya inderaindera kita yang lain yang dapat dikontrol dan dikembangkan. Sang Buddha sering berbicara mengenai faedah mengontrol dan mengembangkan keenam indera. Perbedaan antara indera mata dan indera pikiran ialah bahwa mata berhubungan dengan warna dan benda yang tampak, sedangkan pikiran berhubungan dengan alam pikiran, gagasan serta obyek mental. Dengan lima indera fisik, dapat mengetahui bentuk-bentuk yang terlihat, suara, bebauan, rasa yang melalui lidah dan benda-benda yang dapat disentuh. Gagasangagasan dan konsepsi tidak dapat kita ketahui melalui perantara panca-indera, namun mereka dapat diketahui melalui indera keenam yaitu pikiran. Muncul dan hilangnya pikiran menjelasakan bahwa pikirantidak kekal.

e. Kesadaran (vinnana skhanda)

Pada dasarnya Kesadaran adalah reaksi atau respon dari salah satu indera terhadap obyek-obyek sasaran yang bersangkutan. Kesadaran ini tidak dapat mengenal obyek. Kesadaran hanya berfungsi untuk menyadari adanya suatu obyek. Sebagai contoh : Kalau mata mendapat kontak dengan warna biru, maka kesadaran bangkit dan sadar tentang adanya warna, tetapi belum mengenalnya sebagai 
warna biru. Pencerapan-lah yang dapat mengenal warna itu sebagai warna biru.

Semua fenomena yang dialami oleh batin dan jasmani manusia muncul dan hilang dipengaruhi oleh keadaan sekitar. Batin dan jasmani manusia yang tidak kekal dalam Prajna Paramita Hrdaya Sutra yang dijelaskan oleh Bodhisatva Avalikitesvara disebut sebagai sunya atau kosong. Maksud dari sunya atau kosong adalah berbagai bentukanbentukan yang terbuat dari unsur-unsur yang tidak kekal adalah sunya. Demikian juga dengan batin dan jasmani manusia yang terus berubah mulai dari lahir, tua sakit dan mati.

\section{Sunyata (kekosongan) adalah Nirvana}

Metode filsafat sunyata dipelopori oleh kaum Madyamika yang diwakili oleh Nagarjuna dan Arya Deva pada sekitar abad 1 Masehi. Berdasarkan konsep Anitya Anatma, sunyata menekankan dialeka yang tidak terikat dengan kata-kata, tetapi melihat segala sesuatu dari dua sisi dengan jelas melihat apa adanya di alam fenomena ini.

Sesuatu yang absolut tidak dapat dikatakan dan diterangkan inilah sunyata. Padanan yang mudah dipahami dari sunyata adalah berdiam atau tidak berbicara. Sesuatu yang absolut terbebas dari konsep-konsep dan di luar jangakuan pikiran. Nirvana dikatakan sebagai sunyata yang berarti leburnya kilesa dan keinginan. Tetapi sunyata maupun yang absolut tetap bereksistensi kendati kilesa-kilesa dan keinginan belum dapat dilenyapkan. Sesuatu yang absolut justru diterangkan dalam Pratitytasamutpada, karena hal tersebut tidak nyata dan tampak.

Nirvana dapat dikatakan sebagai sunyata yang berarti leburnya kilesa dan keinginan-keinginan. Namun yang absolut dan sunyata tetap bereksistensi kendatipun klesa-klesa dan keinginan-keinginan belum dapat dilenyapkan. Hukum sebab akibat (pratityasamutpada) menjelaskan sesuatu yang absolut. Guna mengerti kebenaran dunia ini sebagai alat ukurnya dengan dua kebenaran (satya) yaitu kebenaran umum (samvrti satya) dan kebenaran yang mutlak (paramartha satya). 
Fenomena alam ini dicirikan sebagai samvrti, karena menutupi keadaan dari benda-benda. Dilihat dari kacamata paramartha satya, kebenaran samvrti satya merupakan pandangan yang keliru dan semu.

Nirvana jangan ditafsirkan sebagai suatu kekosongan atau kemusnahan karena manusia tidak dapat memahaminya dengan pengertian duniawi. Misalnya seseorang tidak dapat mengatakan bahwa tak ada cahaya, karena orang buta tak dapat melihatnya. Juga seperti dalam sebuah cerita yang terkenal tentang seekor ikan yang berdebat dengan sahabatnya seekor penyu, yang dengan bangga menyatakan bahwa tidak ada daratan. Dalam agama Buddha, Nirvana bukan suatu kekosongan atau keadaan hampa melainkan suatu keadaan yang tidak dapat diungkapkan dengan kata-kata secara tepat.

\section{Bodhisatva mencapai Nirvana dengan kebijaksanaan sejati}

Setelah selesai bermeditasi objek suara Bodhisatva Avalokitesvara merenungkan panca skhanda yg terdiri dari perasaan, pikiran, pencerapan, jasmani dan kesadaran. Ia mengamati bahwa pikiran, perasaan, pencerapan, jasmani, kesadaran dan 6 indra tidak kekal dan trus berubah yg merupakan penderitaan. panca skhanda ini bukan jati dirinya. Setelah itu ia merenungkan jati dirinya yaitu cahaya (hakikat Buddha) bahwa jati dirinya diluar panca skhanda. Karena diluar panca skhanda maka ia bebas dari derita. Jati diri ini diluar dualisme yaitu diluar kehidupan dan kematian, kebahagiaan dan penderitaan, kegagalan dan keberhasilan, kebodohan dan kebijaksanaan. Karena ia memahami jati dirinya hatinya tenang dan tak ada kekhawatiran lagi sehingga ilusi lama kelamaan hilang sehingga tercapailah kesadaran tertinggi.

Setelah mencapai kesadaran tertinggi seorang Bodhisatva sempurna dalam bermeditasi sehingga memiliki prajna yang sempurna. Prajna yang sempurna ditandai dengan pikiran yang tidak pernah salah dan memiliki pandangan benar, sehingga mampu membedakan yang baik dan buruk. Pada keadaan ini seorang Bodhisatva telah menyempurnakan paramita yang terakhir yaitu jhana atau samadhi. Manusia yang hendak 
menyempurnakan paramita maka harus memiliki kebijaksanaan sejati dan menyempurnakan paramita.

\section{Perlaksanaan Prajna Paramita Hdraya Sutra adalah jalan menuju Nirvana}

Prajna Paramita Hdraya Sutra adalah kotbah yang menjelaskan tentang sunya dan sunyata yang menjelaskan tentang fenomena yang dianggap ada tapi sebenarnya tidak ada sesuatu yang dianggap tidak ada sebenarnya ada. Dengan menyadari panca skhanda maka manusia akan menyadari bahwa tubuh ini tidak kekal yang diliputi oleh kemelekatan (tanha) dan kebodohan (avijja).

Kotbah Bodhisatva Avalokitesvara ini bertujuan agar manusia belajar memhami dan mengikis keinginan rendah dan berusaha memunculkan bodhicitta atau pikiran suci agar terbebas dari segala bentuk penderitaan dan kelahiran kembali. Selain menjelaskan tentang kemelekatan Prajna Paramita Hdraya Sutra juga menjelaskan tentang macam-macam penderitaan dan jalan melenyapkan penderitaan.

Manusia yang telah menyadari bahwa segala fenomena yang ada akan lenyap dan muncul kembali disebut dengan penderitaan. Setelah merenungi melalui kebijaksanaan benar maka akan tercapai pikiran yang terang dan damai tidak ada rasa takut, gelisah serta keinginan rendah yang akan mengakibatkan penderitaan. Sutra ini mengajarkan seseorang agar sadar dan menyadri tentang hukum kebenaran bahwa semua yang muncul akan lenyap, yang lahir akan mati dan semua penderitaan itu dapat dilenyapkan dengan menghilangkan kemelekatan.

\section{KESIMPULAN}

Prajna Paramita Hdraya Sutra adalah salah satu kotbah Buddha tentang percakapan antara Bodhisatva Avalokitesvara yang membahas tentang samadhi yang benar untuk mencapai Nirvana. Bodhisatva Avalokitesvara melihat dengan jelas bahwa panca skhanda adalah sunya (kosong). Manusia yang mampu merenungi panca skhanda dengan benar 
maka manusia akan bebas dari sengsara dan derita. Manusia yang telah terbebas dari penderitaan tidak akan timbul lagi kebodohan dan kemelekata.

Pelaksanaan terhadap Prajna Paramita Hdraya Sutra akan membawa kebahagian dan terbabas dari segala bentuk kelahiran dan kematian. Sutra ini menjelaskan bahwa ada dua kondisi di alam semesta yaitu kondisi yang ada tetapi tidak kekal (sunya) dan kondisi yang seakan tidak ada sebenarnya ada (sunyata). Sutra ini juga berisi tentang jalan menuju ke Nirvana. Semua Buddha dan Bodhisava dimasa lampau dan sekarang mencapai kebijaksanaan sejati dengan merenungi panca skhanda.

Prajna Paramita Hdraya Sutra bukanlah mantra yang bisa mengabulkan berkah, jimat yang bisa menghidarkan bencana atau sesuatu yang bisa menolong seseorang dari masalah hidup yang sedang dihadapi. Prajna Paramita Hdraya Sutra disampaikan kepada umat Buddha agar umat Buddha berlatih mengikis kilesa dan tanha agar terbebas dari segala bentuk penderitaan dan mencapai Nirvana. 


\section{Daftar Pustaka}

Buddhism Untuk Pemula, (Online), (http://mahavatar.wordpress.com/buddhismuntuk-pemula/, diakses 28 November 2016).

Hanh, Thich Nhat. Jalur Tua Awan Putih. 2015. Jakarta:Ehipasiko.

Kaharuddin, Pandit.J. 1994. Abhidhammasangaha Jilid Kedua. Jakarta: CV. Nitra Kencana Buana.

Panjika. 1994. Kamus Umum Buddha Dhamma. Jakarta: Tri Sattva Buddhist Centre.

Sumantri, M.U. 1980. Buku Pelajaran Agama Buddha Kebahagiaan Dalam Dhamma. Jakarta: Majelis Buddhayana Indonesia.

Jo Pristana. Pokok-pokok Dasar Mahayana.Yayasan Yasodara Puteri. Jakarta:Ehipasiko.

Suwarto. (1995). Buddha Dhamma Mahayana. Majelis Agama Buddha Mahayana Indonesia. Jakarta.

Sri Dhammananda. (2005). Keyakinan Umat Buddha. Yayasan penerbit Karaniya. Jakarta. 